\begin{tabular}{|c|c|}
\hline Title & The Purity and Thermal Stability in A ir of Metal-Encapsulating Carbon Nanocapsules (MECNCs) \\
\hline Author(s) & $\begin{array}{l}\text { Uo, Motohiro; Kachi, Hanako; A kasaka, Tsukasa; W atari, Fumio; Sato, Y oshinori; Motomiya, Kenichi; Tohji, } \\
\text { Kazuyuki }\end{array}$ \\
\hline Citation & $\begin{array}{l}\text { Fullerenes Nanotubes and Carbon Nanostructures, 15(4), 303-309 } \\
\text { https://doi.org/10.1080/15363830701423773 }\end{array}$ \\
\hline Issue Date & 2007-07 \\
\hline Doc URL & http:/hdl.handle.net/2115/38741 \\
\hline Rights & $\begin{array}{l}\text { This is an electronic version of an article published in Fullerenes, Nanotubes and Carbon Nanostructures, V olume 15, } \\
\text { Issue 4, 2007, pp. 303-309. Fullerenes, Nanotubes and Carbon Nanostructures is available online at: } \\
\text { http://www.informaworld.com/openurl?genre=article\& issn=1536-383X \& volume=15\& issue=4\& spage=303 }\end{array}$ \\
\hline Type & article (author version) \\
\hline File Information & FNCN15-4.pdf \\
\hline
\end{tabular}

Instructions for use 


\title{
The purity and thermal stability in air of metal-encapsulating carbon nanocapsules (MECNCs)
}

\author{
Motohiro Uo*, Hanako Kachi, Tsukasa Akasaka and Fumio Watari \\ Department of Biomedical Materials and Engineering, Graduate School of Dentistry, Hokkaido University, 060-8586, \\ Sapporo, Japan
}

Yoshinori Sato, Kenichi Motomiya and Kazuyuki Tohji

Graduate School of Environmental Studies, Tohoku University, 980-8579, Sendai, Japan

* corresponding author (Motohiro Uo)

Department of Biomedical Materials and Engineering, Graduate School of Dentistry,

Hokkaido University, 060-8586, Sapporo, Japan

Tel \& fax: +81-11-706-4251_E-mail address: uo@den.hokudai.ac.jp

\begin{abstract}
Rare earth elements (Y, La, Ce, Nd, Gd and Dy) encapsulated by carbon nanocapsules (CNCs) were synthesized and their purity and air oxidation stability were estimated. The purity was estimated as the rare earth carbide content. Gd- and Dy-encapsulating CNCs had higher than $30 \mathrm{wt} \%$ and others 15 to $20 \mathrm{wt} \%$. Encapsulated rare earth carbide was oxidized by heating in air at $400^{\circ} \mathrm{C}$ or higher. This suggested oxidation damage to the graphene capsules of CNCs.
\end{abstract}

Keywords: Metal encapsulating carbon nanocapsules, rare earth, carbide, purity, thermal stability

\section{INTRODUCTION}

Metal-encapsulating carbon nanocapsules (MECNCs) are several tens of nanometers in diameter and consist of a graphene sheet structure encapsulating a metallic carbide. MECNCs have a surface covered by a graphene sheet, so they have quite high chemical stability (1-10). In the capsule synthesized by using a direct current arc-discharge method with a lanthanide-loading graphite anode, lanthanide is usually encapsulated as a carbide. The formation of MECNCs was suggested as the segregation of excess carbon composition from the metal carbide droplets while they are cooling (4). Metallofullerenes have been studied as contrast agents in X-ray or magnetic resonance imaging (11, 12). MECNCs also contain metallic elements in the graphite capsule, but the size of the capsule and the amount of encapsulated metallic elements are a hundred times larger than metallofullerenes. In addition, the graphene capsules have high chemical stability and the encapsulated metals are stable in air, water and concentrated sulfuric acid, and these features will provide higher imaging and tracing efficiencies as contrast agents or tracers as the authors have reported the low cytotoxicity of MECNCs (13). In the application of MECNCs, their purity and the chemical stability of the graphene capsules must be estimated.

\section{EXPERIMENTAL PROCEDURES}

MECNCs were synthesized by a direct current arc-discharge between a pure graphite cathode and a metal-loaded graphite anode in a helium atmosphere. A pure graphite rod (purity 99.9\%, Wakomu Denso Co., Japan) and a graphite rod loaded with $\mathrm{Y}_{2} \mathrm{O}_{3}, \mathrm{La}_{2} \mathrm{O}_{3}, \mathrm{CeO}_{2}, \mathrm{Nd}_{2} \mathrm{O}_{3}, \mathrm{Gd}_{2} \mathrm{O}_{3}$ and $\mathrm{Dy}_{2} \mathrm{O}_{3}$ powder $(99.9 \%$, Wako Pure Chemical Industries, Japan) as the source of rare earth were used as the cathode and anode, respectively. The arc-discharge was carried out in helium gas at 500 Torr. A carbonaceous deposit on the cathode was corrected and the synthesis of the MECNCs was confirmed with TEM observation (TEM: Hitachi, HF-2000, Japan), energy-dispersive X-ray spectroscopy analysis (EDXS: NORAN Instruments, VANTAGE, USA) and X-ray diffraction (XRD: Rigaku, Multiflex, Japan). As-grown MECNCs, MECNCs heated at 350 to $450^{\circ} \mathrm{C}$ in air for 30 minutes and MECNCs heated at $450^{\circ} \mathrm{C}$ in vacuum $\left(10^{-6}\right.$ torr $)$ were subjected to X-ray diffraction to estimate the crystalline state of encapsulated rare earth. Some MECNCs were heated at $800^{\circ} \mathrm{C}$ for 2 hours to burn out the graphene capsule and the rare earth oxide that 
remained was weighed. The rare earth carbide contents in as-grown MECNCs were converted from the final oxide weight and the chemical formulae of the rare earth carbides and oxides were assigned.

\section{RESULTS AND DISCUSSION}

MECNCs encapsulating Y, La, Ce, Nd, Gd and Dy were successfully synthesized. Below, those MECNCs are abbreviated as Y-CNCs. Figure 1 shows the TEM image of Ce-CNCs. We observed many MECNCs as well as non-encapsulating carbon nanocapsules. The single-crystal $\mathrm{CeC}_{2}$ compounds were encapsulated in the multi-walled carbon layers. The fact that the $\mathrm{CeC}_{2}$ interior was single-crystalline was confirmed by electron diffraction (9) and EDXS. The estimated rare earth carbide contents in various MECNCs are presented in Table 1. The weights of the MECNCs were mostly obtained from the rare earth carbide cores. Therefore, the carbide contents were close to the purity of the MECNCs. The purity levels of Gd- and Dy-containing CNCs were more than $30 \mathrm{wt} \%$ and others were less than $20 \mathrm{wt} \%$. Therefore, graphite, amorphous carbon and vacant carbon nanocapsules were contained as impurities.

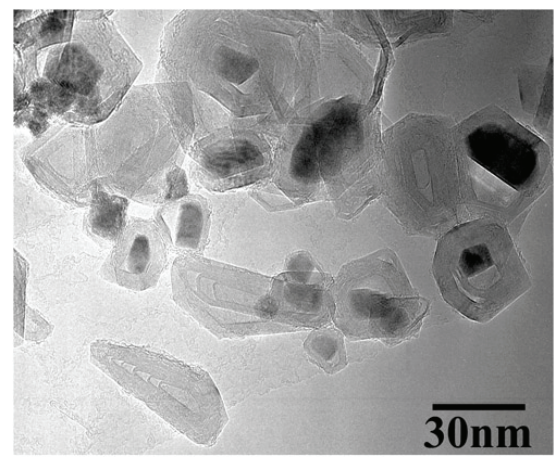

Figure.1 High magnification TEM image of MECNCs (Ce-CNCs)

Table 1. Rare earth carbide content in raw MECNCs.

\begin{tabular}{c|c|c}
\hline MECNCs & Chemical formula of encapsulated carbide & Carbide content (wt\%) \\
\hline Y-CNCs & $\mathrm{YC}_{2}$ & 16 \\
La-CNCs & $\mathrm{LaC}_{2}$ & 19 \\
Ce-CNCs & $\mathrm{CeC}_{2}$ & 19 \\
Nd-CNCs & $\mathrm{NdC}_{2}$ & 20 \\
Gd-CNCs & $\mathrm{GdC}_{2}$ & 35 \\
Dy-CNCs & $\mathrm{DyC}_{2}$ & 31 \\
\hline
\end{tabular}

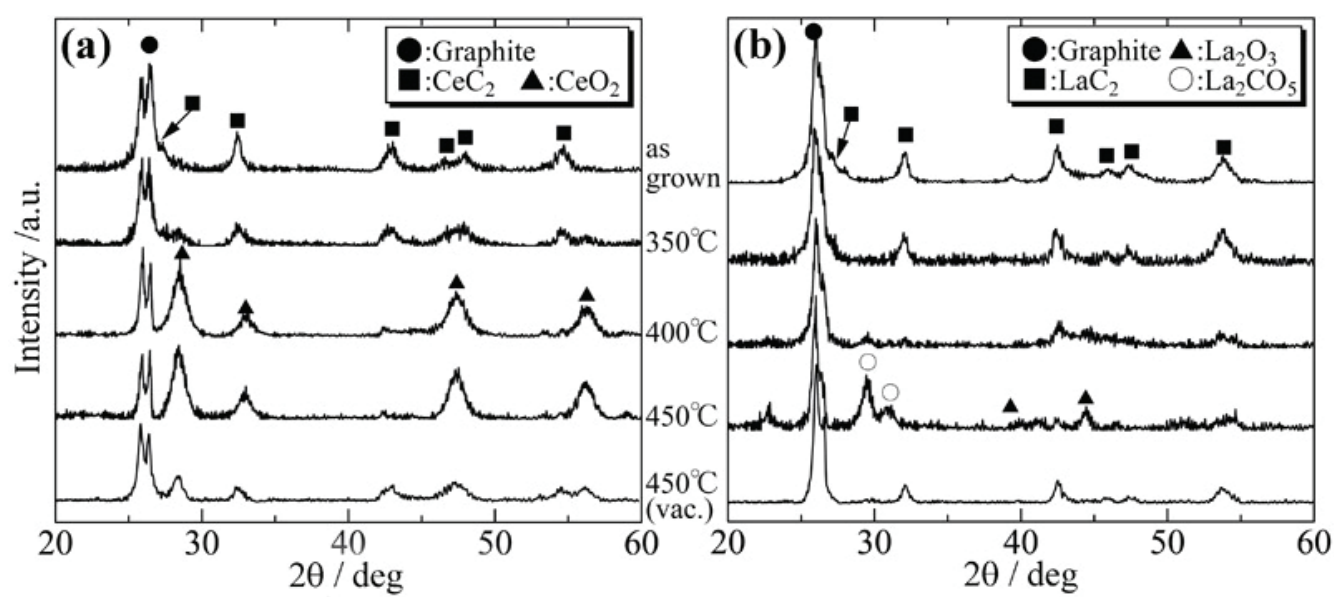

Figure.2 Changes in X-ray diffraction spectra of Ce- and La-CNCs with heat treatment.

Figure 2(a) shows the $\mathrm{X}$-ray diffraction spectra of Ce-encapsulating nanocapsules (Ce-CNCs) as grown and heated at 350 to $450^{\circ} \mathrm{C}$. As-grown Ce-CNCs show diffraction peaks derived from the graphite and $\mathrm{CeC}_{2}$. The spectrum was not changed after heating at $350^{\circ} \mathrm{C}$, but $\mathrm{CeO}_{2}$ appeared after heating at higher than $400^{\circ} \mathrm{C}$. Rare earth carbides are instable in air and easily oxidized. In MECNCs, however, the graphene capsule is airtight, therefore the rare earth carbide is isolated from the air. When heated at higher than $400^{\circ} \mathrm{C}$ in air, the graphene capsule was damaged by oxidation and the encapsulated $\mathrm{CeC}_{2}$ was oxidized to $\mathrm{CeO}_{2}$. Similarly, Y-CNCs showed peaks derived from the oxide species $\left(\mathrm{Y}_{2} \mathrm{O}_{3}\right)$ after heating at $400^{\circ} \mathrm{C}$ or higher. Figure 2(b) shows the X-ray diffraction spectra of $\mathrm{La}-\mathrm{CNCs}$ as grown and heated at 350 to $450^{\circ} \mathrm{C}$. As-grown La-CNCs show diffraction peaks derived from the graphite and $\mathrm{LaC}_{2}$. After heating at $400^{\circ} \mathrm{C}$, peaks of $\mathrm{LaC}_{2}$ became weak and peaks of $\mathrm{La}_{2} \mathrm{O}_{3}$ and $\mathrm{La}_{2} \mathrm{CO}_{5}$ appeared at above 
$450^{\circ} \mathrm{C}$. Nd-CNCs showed $\mathrm{Nd}_{2} \mathrm{O}_{2} \mathrm{CO}_{3}$ after $450^{\circ} \mathrm{C}$. These results showed that La- and Nd-CNCs were stable at lower than $350^{\circ} \mathrm{C}$ and that carbonate or oxicarbonate species were formed at $450^{\circ} \mathrm{C}$. After heating at $450^{\circ} \mathrm{C}$ in vacuum, $\mathrm{Ce}-\mathrm{CNCs}$ showed $\mathrm{CeO}_{2}$ peaks, however, La-CNCs were not changed. Also, Y-CNCs and Nd-CNCs were not changed after heating at $450^{\circ} \mathrm{C}$ in vacuum. Then, Ce-CNCs would be less stable for heating.

Figure.3 Changes in X-ray diffraction spectra of Dy- and Gd-CNCs with heat treatment.

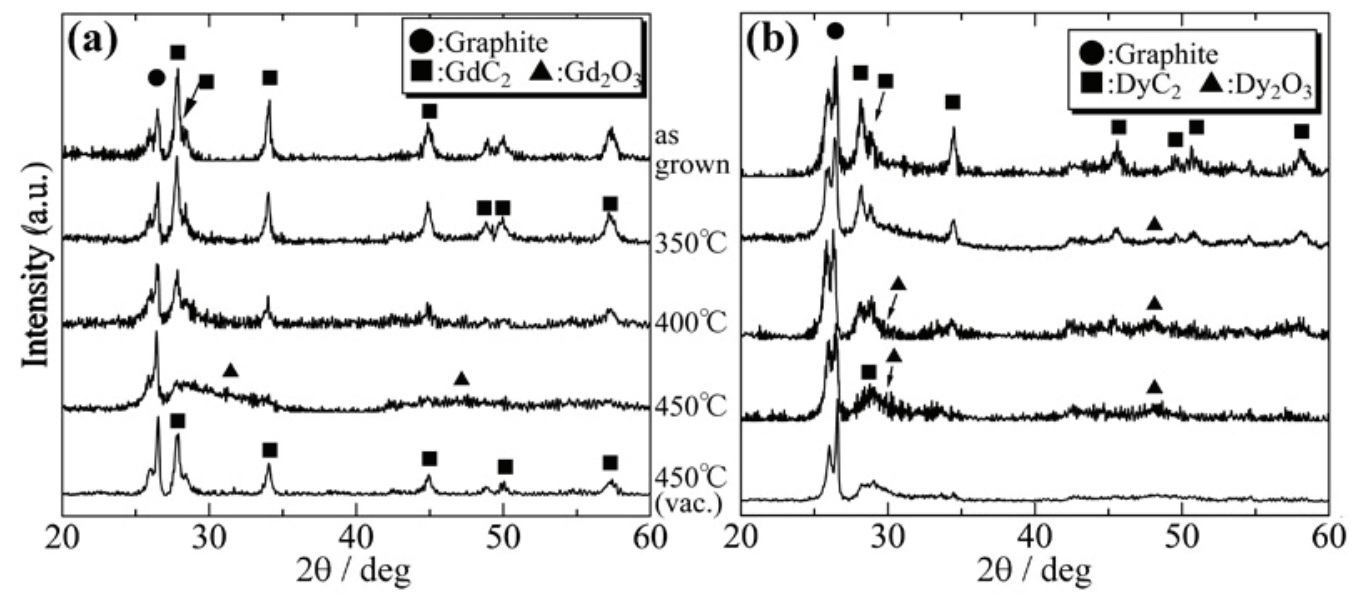

Figure 3(a) shows the X-ray diffraction spectra of Gd-CNCs as grown and heated at 350 to $450^{\circ} \mathrm{C}$. The peaks derived from $\mathrm{GdC}_{2}$ remained after heating at $400^{\circ} \mathrm{C}$. At $450^{\circ} \mathrm{C}$, peaks assigned to $\mathrm{GdC}_{2}$ disappeared and unclear peaks assigned to $\mathrm{Gd}_{2} \mathrm{O}_{3}$ were slightly increased. $\mathrm{Gd}-\mathrm{CNCs}$ was not changed after heated at $450^{\circ} \mathrm{C}$ in vacuum. As shown in Figure 3(b), the peaks derived from $\mathrm{DyC}_{2}$ remained after heating at $400^{\circ} \mathrm{C}$, but the peaks were broadened. Dy-CNCs after heated at $450^{\circ} \mathrm{C}$ in vacuum was similar to that after heated in air. Therefore, Gd-CNCs would have the highest stability for heating in air and vacuum.

Figure 4 shows the TEM images of Gd- and Dy-CNCs after heated at $450^{\circ} \mathrm{C}$. Gd or Dy encapsulating CNCs (point 1 and 3 in Figure 4) were remained and large granules (point 2 and 4) were generated after heating. The compositions of each point analyzed by EDXS were tabulated in Table 2. Point 1 and 3 contain the rare earth (Gd or Dy) and C. Then, the remaining of Gd- and Dy-CNCs after heated at $450^{\circ} \mathrm{C}$ could be confirmed. Point 2 and 4 which were generated large granules showed high oxygen content. Those granules could be assumed that the most of MECNCs were oxidized and degraded by heating, and then
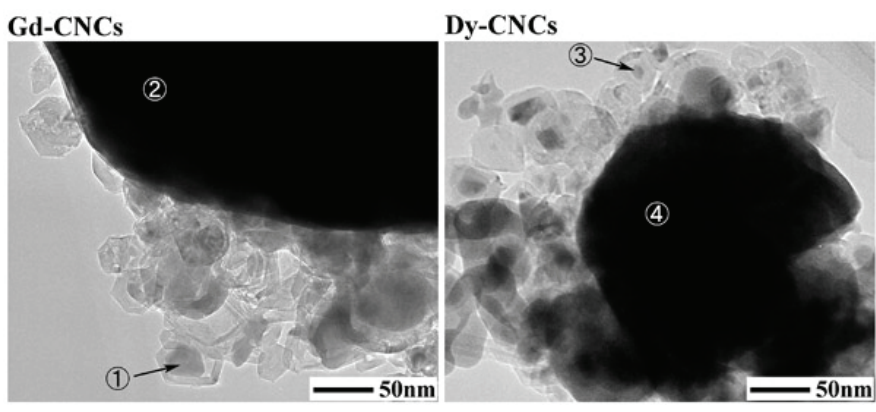

Figure.4 TEM images of Dy- and Gd-CNCs after heat treatment at $450^{\circ} \mathrm{C}$. encapsulated rare earth was formed oxide particles. In Y-, La-, Ce- and Nd-CNCs that showed no carbides in XRD spectra after heated at $450^{\circ} \mathrm{C}$, the remained MECNCs could not observed by TEM observation. Therefore, the heating stability estimated by XRD was confirmed by TEM observation.

Table 2. EDXS analysis of Gd- and Dy-CNCs after heated $450^{\circ} \mathrm{C}$ shown in Figure 4 (at\%)

\begin{tabular}{rccccc}
\hline Analyzed point & Elements & Gd & Dy & C & O \\
\hline 1 & & & & \\
\hline 2 & 7.0 & ---- & 92.4 & 0.6 \\
\hline 3 & 10.6 & ---- & 66.1 & 23.3 \\
\hline 4 & ---- & 76.9 & 20.9 & 2.2 \\
\hline
\end{tabular}

Oxidation treatment at around $500^{\circ} \mathrm{C}$ was useful for the purification of carbon nanotubes because the impurities, e.g. amorphous carbon or hydrocarbon, were burned out before nanotube oxidation. In this study, the encapsulated 
rare earth carbides in MECNCs were oxidized by heating at 400 to $450{ }^{\circ} \mathrm{C}$ in air. Ajayan et al. suggested that both the strain at the tip and the presence of pentagons might help to initiation of the oxidation at the caps of carbon nanotubes (14). MECNCs have tips which would contain pentagons, thus, heating in air would promote the oxidation at the tips of the graphene capsules of MECNCs and airtightness is lost. Then the encapsulated rare earth carbide is oxidized. The airtightness of the graphene capsule means that the encapsulated elements are isolated from the outside. Oxidation of encapsulated rare earth elements indicates damage to the graphene capsules and loss of their airtightness. Therefore, MECNCs heated at higher than $400^{\circ} \mathrm{C}$ in air lose their chemical stability and the encapsulated elements become erosive. In other words, MECNCs are stable at lower than $350^{\circ} \mathrm{C}$ and the erosion of encapsulated elements is negligible. This feature is important for biomedical application as the authors have reported the low cytotoxicity of $\mathrm{Ce}-\mathrm{CNCs}(13)$. In this study, various rare earth elements were encapsulated in carbon nanocapsules. Gd-CNCs had the highest purity ( $35 \mathrm{wt} \%$ ) among the synthesized MECNCs and slightly better stability for heating in air up to $450^{\circ} \mathrm{C}$. Concerning to the Gd-CNCs, paramagnetic propery and magnetic separation was suggested $(15,16)$. Thus, Gd-CNCs would be favorable for biomedical and other applications.

\section{ACKNOWLEDGEMENTS}

This work was supported by Research on Advanced Medical Technology in Health and Labour Sciences Research Grants from the Ministry of Health, Labour and Welfare of Japan. A part of this study was also supported by Grant-in-Aid for Scientific Research (B) No.18390509 from the Ministry of Education, Culture, Sports, Science and Technology, Japan.

\section{References}

(1) Ruoff R.S., Lorents D.C., Chan B., Malhotra R. and Subramoney S. (1993) Single crystal metals encapsulated in carbon nanoparticles. Science. 259: 346

(2) Tomita M., Saito Y. and Hayashi T. (1993) $\mathrm{LaC}_{2}$ encapsulated in graphite nano-particle. Jpn J. Appl. Phys. 32: L280.

(3) Yosida Y. (1993) Synthesis of $\mathrm{CeC}_{2}$ crystals encapsulated within gigantic super fullerenes. Appl. Phys. Lett. 62: 3447.

(4) Saito Y., Yoshikawa T., Okuda M., Ohkohchi M., Ando Y., Kasuya A. and Nishina Y. (1993) Synthesis and electron-beam incision of carbon nanocapsules encaging $\mathrm{YC}_{2}$. Chem. Phys. Lett. 209: 72.

(5) Seraphin S., Zhou D., Jiao J., Withers J.C. and Loutfy R. (1993) Selective encapsulation of the carbides of yttrium and titanium into carbon nanoclusters. Appl. Phys. Lett. 63: 2073.

(6) Saito Y., Okuda M., Yoshikawa T., Bandow S., Yamamuro S., Wakoh K., Sumiyama K. and Suzuki K. (1994) Synthesis of $\mathrm{Sc}_{15} \mathrm{C}_{19}$ crystallites encapsulated in carbon nanocapsules by arc evaporation of Sc-C composite. Jpn. J. Appl Phys. 33: L186.

(7) Funasaka H., Sugiyama K., Yamamoto K. and Takahashi T. (1995) Synthesis actinide carbides encapsulated within carbon nanoparticles. J. Appl. Phys. 78: 5320.

(8) Pasqualini E., Adelfang P. and Regueiro M.N. (1996) Carbon nanoencapsulation of uranium dicarbide. J. Nuclear Materials $231: 173$.

(9) Yosida Y. (1997) A new type of ultrafine particles : rare earth dicarbide crystals encapsulated in carbon nanocages. Physica B229: 301.

(10) Sato Y., Jeyadevan B., Hatakeyama R., Kasuya A. and Tohji K. (2004) Electronic properties of radial single-walled carbon nanotubes. Chem. Phys. Lett. 385: 323.

(11) Mikawa M., Kato H., Okumura M., Narazaki M., Kanazawa Y., Miwa N. and Shinohara H. (2001) Paramagnetic Water-Soluble Metallofullerenes Having the Highest Relaxivity for MRI Contrast Agents. Bioconjugate Chem. 12: 510.

(12) Bolskar R.D., Benedetto A.F., Husebo L.O., Price R.E., Jackson E.F., Wallace S., Wilson L.J. and Alford M. (2003) First Soluble $\mathrm{M} @ \mathrm{C}_{60}$ Derivatives Provide Enhanced Access to Metallofullerenes and Permit in Vivo Evaluation of $\mathrm{Gd} @ \mathrm{C}_{60}\left[\mathrm{C}(\mathrm{COOH})_{2}\right]_{10}$ as a MRI Contrast Agent. J. Am. Chem. Soc. 125: 5471.

(13) Uo M., Tamura K., Sato Y., Yokoyama A., Watari F., Totsuka Y. and Tohji K. (2005) The cytotoxicity of metal-encapsulating carbon nanocapsules. Small 1: 816.

(14) Ajayan P.M., Ebbesen T.W., Ichihashi T., Iijima S., Tanigaki K. and Hiura H. (1993) Opening carbon nanotubes with oxygen and implications for filling. Nature 362: 522

(15) Majetich S.A., Artman J.O., McHenry M.E., Nuhfer N.T. and Staley S.W. (1993) Preparation and properties of carbon-coated magnetic nanocrystallites. Phys. Rev. B 48: 16845

(16) Subramoney S., Ruoff R.S., Lorents D.C., Chan B., Malhotra R., Dyer M.J. and Parvin K. (1994) Magnetic separation of GdC 2 encapsulated in carbon nanoparticles. Carbon 32: 507 